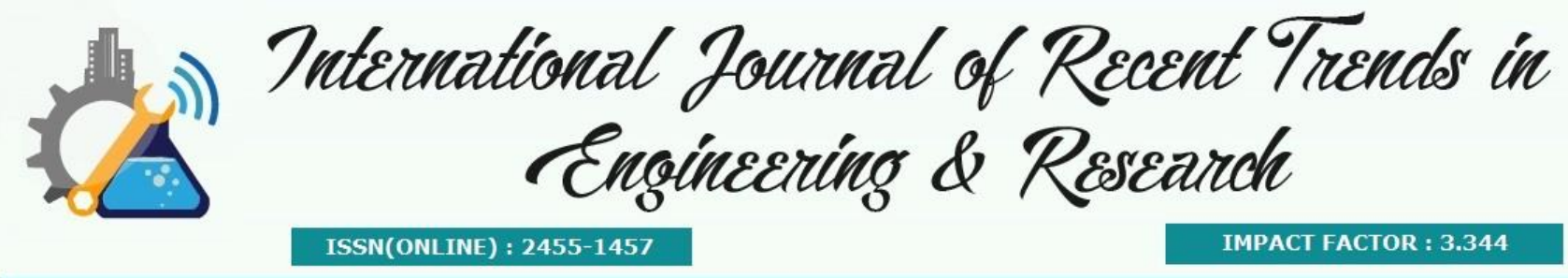

\title{
Fuzzy Logic Concept in Technology, Society, and Economy Areas in Predicting Smart City
}

\author{
Mochammad Iswan Perangin-angin ${ }^{1}$, Khairul ${ }^{2}$, Andysah Putera Utama Siahaan ${ }^{3}$ \\ Faculty of Computer Science \\ Universitas Pembangunan Panca Budi \\ Jl. Jend. Gatot Subroto Km. 4,5 Sei Sikambing, 20122, Medan, Sumatera Utara, Indonesia
}

\begin{abstract}
In the concept of predicting the town toward smart city using fuzzy Tsukamoto, several parameters need to be processed for the feasibility of a smart city. The process of calculating the predicted value of a city towards smart city based on the rules that are made of the value of membership and fuzzy domain. After the calculation, it will get the predicted value of the appropriateness of all town called the smart city. In the concept of predicting smart city, there are 19 rules are used. If every city has variable 1 is not feasible, the city can be called the city worth heading smart city. If there is a variable 2 found not feasible, then the city is still in need of improvement with so-called cities were not yet eligible to the Smart city, whereas if the variable 3 found not feasible, the city is not eligible to get the smart city.
\end{abstract}

Keywords - Fuzzy Logic, Membership Function, Smart City

\section{INTRODUCTION}

Development of the city shown by population growth and activities in the city demanding that the greater land requirements. It is evidenced by the level of use of land for residential areas, along with the high rate of population growth in natural and migration, and diversity of demands.

Growing town feared to cause problems sporadically in the suburban area [6]. Government and private developers are only focused on addressing the housing needs of the urban community. Housing development spread both horizontally and vertically performed by different actors implementing the value-oriented cheap land, which even often on land that is still functioning as a productive irrigated lands. Development is done by giving priority to land that has access to and from the main road, even to cross the administrative region inter-city or inter-district.

Smart city concept has been initiated and implemented in the cities of developed countries since the beginning of the new millennium ago. This phenomenon can not be separated from the progress of Internet technology began to be used in many aspects of life at the time [7][8]. The Internet that was originally only used by governments and academics, then growing very rapidly until recently a massmedia communications and transactions that affect all aspects of life.

There are many definitions of smart city stating that the city would be smart if the investment in human resources and social capital and infrastructure communication systems of traditional and modern can boost sustainable economic growth and quality of life, with the management of natural resources wisely, through ordinances participatory governance. There is also explained that the smart city is a specific geographical area where advanced technologies such as ICT, logistics, energy production, and other, complement each other in order to create benefits for the residents of the city in terms of wellbeing, participation, quality of the environment, the development of intelligent, which is managed by the orderly governance with good policies. 
In essence, the smart city concept is the use of digital data and information systems technology in large-scale planning and urban management. In this definition the major cities in the world have started to recognize and use digital data as input in the management of the city. However, over the times, the concept of smart cities to change and variation.

\section{THEORIES}

According to the terminology, "center" is a region that is placed at the midpoint, or an area in the middle of the huge region [7]. Another sense of "center" is a place where regular activities are concentrated Suburban is the area where or area where the commuters live not far from the city center. Commuter is the people who live in the suburbs who commute to the city to work every day.

City Center is the area of town that is used as the center of activity, economy, government and culture. This region is also called the Central Business District while the suburban is the area around the city center which serves as a residential area. The concept of suburban often given meaning or translated with "fringe." More precisely, the suburb is an intermediate form between rural and urban [6]. The suburban area is an area located between or in the middle of the rural area. If viewed as a community, it is a suburban community group who have properties midway between rural and urban.

\section{A. $\quad$ Methodology}

\section{PROPOSED WORK}

Fuzzy logic is a proper way to map an input space into an output space. A reason to use fuzzy logic is easier to understand these and fuzzy logic if there are incorrect data have a tolerance.

In general, the fuzzy logic system has four elements:

* The basic rule that contains the rules derived from the experts.

* A decision-making mechanism in which the expert took the decision to apply the knowledge they have.

* A Fuzzification process that converts the amount into the magnitude fuzzy crisp.

* A Defuzzification Process which is the reverse of the process that is changing the fuzzification magnitude result of the fuzzy inference engine, being the amount of crisp.

In the implementation of the system, fuzzy has three parts, namely fuzzification, fuzzy inference, and defuzzification. However, the process here is optional defuzzification, i.e., when the conclusion is already meeting or as expected, then no defuzzification process [2][3]. However, if a conclusion has not met the defuzzification process is still being done.

Fuzzy logic membership functions consisting of boundary value data input and data output values [1][4]. The definition of the membership function is a graph that there are points of boundary value data input into a valuable membersHIP VALUE BETWEEN 0 AND 1.

In the graph membership functions, there are three sections, namely core (core), support, and boundary (the boundary). Part cores or core part graph is representing the complete area of the entire set of fuzzy, so if expressed in a function where $\mathrm{x}$ is a member of the set $\mu(\mathrm{x})=1$. Furthermore, the second part is the support, the support or the support of a part graph representing the region with a membership value of the fuzzy set is not 0 , then if expressed in a function where $\mathrm{x}$ is a member of the set $\mu(\mathrm{x})>0$. Moreover, lastly, part of boundary or limit. Boundary in the graph membership functions declared the value of the minimum and maximum limits of the fuzzy set, then it if expressed in a function where $\mathrm{x}$ is a member of the set is $0<\mu(\mathrm{x})>1$.

Tsukamoto Fuzzy method is a method of Fuzzy Inference System of the system decision makers [5]. 
In the method of using the Tsukamoto fuzzy rules or rules shaped "causation" or "if-then." The calculation method of fuzzy Tsukamoto, the first rule is formed representing the fuzzy set, then calculate the degree of membership by the rules that have been created. After getting a degree of membership value, look for the value of the predicate alpha $(\alpha)$ by finding the minimum value of the value of the degree of membership. The final step, look for the value output is crisp values $(\mathrm{z})$ called defuzzification process, which is expressed in the equation 1.

Where:

$$
\mathrm{Z}=\frac{\sum_{0}^{1} \alpha(i) \cdot z(i)}{\sum_{0}^{1} z(i)}
$$

$\alpha=$ alpha predicate (the minimum value of the degree of membership is)

$\mathrm{Zi}=$ crisp values obtained from the formula degree of membership of fuzzy sets which is the value of output

$\mathrm{Z}=$ the average defuzzyfication centralized (Center Average Defuzzyfier).

\section{B. $\quad$ Smart City Elements}

There are several elements in developing a smart city, such as:

a. Smart Government. Key to the success of government is good governance, among others, paradigms, systems and processes of governance and development heed the principles of the rule of law.

b. Smart Economy. It means that the higher the innovations that improved it will add new business opportunities and increase market competition of business/capital.

c. Smart Mobility. Management of municipal infrastructure developed in the future is an integrated management system to ensure alignment with the public interest.

d. Smart People. Development is always in need of capital, both economic capital, human capital and social capital.

e. Smart Living. The smart environment means an environment that can provide comfort, sustainability of resources, the beauty of the physical and non-physical, visual or otherwise, for the community and the public.

f. Smart Life. Cultured, means that humans have a measurable quality of life.

\section{EVALUATION}

Each town has a different value for each element or specifications of the smart city. After the discovery of the elements or specifications of the smart city, the next stage is to enter a value into the membership function in fuzzy logic methods. The fuzzy method chosen is Tsukamoto. The following table describes the variables involved in smart city concept.

Table 1 Smart city variable

\begin{tabular}{|c|c|}
\hline Function & Variable Name \\
\hline \multirow{4}{*}{ Input } & Government \\
\cline { 2 - 2 } & Economy \\
\cline { 2 - 2 } & Mobility \\
\cline { 2 - 2 } & People \\
\cline { 2 - 2 } & Living \\
\cline { 2 - 2 } & Life \\
\hline Output & Estimation Value \\
\hline
\end{tabular}


Determining Domain Fuzzy's concept of smart city is in Table 2.

Table 2 Domain

\begin{tabular}{|l|c|c|}
\hline Variable & Classification & Range \\
\hline \multirow{4}{*}{ Government } & BAD & $<50$ \\
\cline { 2 - 3 } & AVERAGE & $50<\mathrm{x}<79$ \\
\cline { 2 - 3 } Economy & GOOD & $>79$ \\
\hline & BAD & $<50$ \\
\cline { 2 - 3 } & AVERAGE & $50<\mathrm{x}<79$ \\
\cline { 2 - 3 } Mobility & GOOD & $>79$ \\
\cline { 2 - 3 } & BVERAGE & $50<\mathrm{x}<79$ \\
\cline { 2 - 3 } People & GOOD & $>79$ \\
\hline \multirow{4}{*}{ Living } & BAD & $<50$ \\
\cline { 2 - 3 } & AVERAGE & $50<\mathrm{x}<79$ \\
\cline { 2 - 3 } & GOOD & $>79$ \\
\hline \multirow{4}{*}{ Life } & BVAD & $<50$ \\
\cline { 2 - 3 } & AVERAGE & $50<\mathrm{x}<79$ \\
\cline { 2 - 3 } & GOOD & $>79$ \\
\cline { 2 - 3 } & BVAD & $<50$ \\
\cline { 2 - 3 } & GVRAGE & $50<\mathrm{x}<79$ \\
\hline
\end{tabular}

The membership functions for the smart city are shown in the following formulas.

$$
\begin{aligned}
& \mu_{\mathrm{BAD}}[\mathrm{x}] \quad=\left\{\begin{array}{cc}
1 ; & x \leq 50 \\
\frac{40-x}{35} ; & 50 \leq x \leq 79 \\
0 ; \quad x \geq 79
\end{array}\right. \\
& \mu_{\text {AVERAGE }[\mathrm{X}]}=\left\{\begin{array}{c}
1 ; \quad x=79 \\
\frac{x-5}{35} ; \quad 50 \leq x \leq 79 \\
\frac{70-x}{30} ; 79 \leq x \leq 100 \\
0 ; x \leq 50 \text { atau } x \geq 79
\end{array}\right.
\end{aligned}
$$

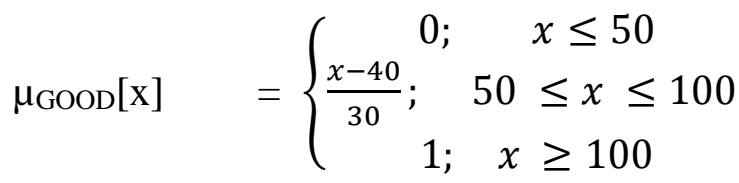

To get a prediction of all the city toward the smart city based on the variables above, the following rules must be formed. 


\section{Table 3 Prediction Rules}

\begin{tabular}{|c|c|c|c|c|c|c|c|}
\hline R & V1 & V2 & V3 & V4 & V5 & V6 & V7 \\
\hline R1 & G & G & G & G & G & G & G \\
\hline R2 & G & G & G & G & G & A & G \\
\hline R3 & G & G & G & G & A & G & G \\
\hline R4 & G & G & G & A & G & G & G \\
\hline R5 & G & G & A & G & G & G & G \\
\hline R6 & G & A & G & G & G & G & G \\
\hline R7 & A & G & G & G & G & G & G \\
\hline R8 & G & G & G & G & A & A & G \\
\hline R9 & G & G & G & A & A & G & G \\
\hline R10 & G & G & A & A & G & G & G \\
\hline R11 & G & A & A & G & G & G & G \\
\hline R12 & A & A & G & G & G & G & G \\
\hline R13 & G & G & G & A & A & A & A \\
\hline R14 & G & G & A & A & A & G & A \\
\hline R15 & G & A & A & A & G & G & A \\
\hline R16 & A & A & A & G & G & G & A \\
\hline R17 & G & G & A & A & A & A & B \\
\hline R18 & G & A & A & A & A & G & B \\
\hline R19 & A & A & A & A & G & G & B \\
\hline
\end{tabular}

Defuzzification means for converting fuzzy set firmly. Fuzzy results can not be used as for applications; it is necessary to convert the number to the number of fuzzy sets decisively for further processing. It is used to achieve results by using defuzzification process. Defuzzification can reduce up to the quantity of single-valued fuzzy or as a set or convert it to a form that fuzzy quantity present. Defuzzification is called as a method of "rounding" as well.'

Defuzzification is a step taken to get the set firmly against the city predictive ratings to the smart city based on the Government, Economy, Mobility, People, Living, and Life. The method used is the weighted average fuzzy. To calculate the value of the predicate ( $\alpha$-predicate) predictive assessment town toward smart city based on an existing variable, while the equation is as follows:

$$
Z=\frac{\propto_{-} \text {pred } 1 * Z 1+\propto_{-} \text {pred } 2 * Z 2+\propto_{-} \text {pred } 3 * Z 3+\propto_{-} \text {pred } 4 * Z 4}{\propto_{-} \text {pred } 1+\alpha_{-} \text {pred } 2+\alpha_{-} \text {pred } 3+\alpha_{-} \text {pred } 4}
$$

\section{CONCLUSION}

Smart city is a concept in which a city has an integrated structure. To get the order of the city such as, objective assessment is required. There are several parameters that become the benchmark assessment. Fuzzy method plays a major role in determining whether a city worth getting that value. Fuzzy logic can help the appraiser to determine the repairs sector in particular side. Cities which do not meet certain requirements should be improved based on the values obtained in perhitunggan fuzzy. Some elements can be a reference for the assessment.

\section{REFERENCES}

[1] A. P. U. Siahaan, "Fuzzification of College Adviser Proficiency Based on Specific Knowledge," International Journal of Advanced Research in Computer Science and Software Engineering, vol. 6, no. 7, pp. 164-168, 2016. 
[2] L. Biacino and G. Gerla, "Fuzzy Logic, Continuity and Effectiveness," Mathematical Logic, vol. 41, p. 643-667, 2002.

[3] G. Gerla, "Effectiveness and Multivalued Logics," The Journal of Symbolic Logic, vol. 71, pp. 137-162, 2006.

[4] S. S. Jamsandekar and R. R. Mudholkar, "Fuzzy Classification System by Self Generated Membership Function Using Clustering," International Journal of Information Technology, vol. 6, no. 1, pp. 697-704, 2014.

[5] P. Hájek, "Fuzzy Logic and Arithmetical Hierarchy," Fuzzy Sets and Systems, vol. 73, pp. 359-363, 1994.

[6] W. Purnomowati and Ismini, "Konsep Smart City dan Pengembangan Pariwisata di Kota Malang," JIBEKA, vol. 8, no. 1, pp. 65-71, 2014.

[7] R. Dameri, "Searching for Smart City Definition: a Comprehensive Proposal," International Journal of Computers \& Technology, vol. 11, no. 5, pp. 2544-2551, 2013.

[8] A. Coe, G. Paquet and J. Roy, "E-Governance and Smart Communities: A sosial Learning Challenge," Social Science Computer Review, vol. 19, no. 1, pp. 80-93, 2001. 